\title{
Marginal fit of all-ceramic crowns fabricated using two extraoral CAD/CAM systems in comparison with the conventional technique
}

This article was published in the following Dove Press journal:

Clinical, Cosmetic and Investigational Dentistry

16 March 2017

Number of times this article has been viewed

\author{
Fawaz Alqahtani ${ }^{1,2}$ \\ 'Department of Prosthodontics, \\ ${ }^{2}$ Higher Education and Scientific \\ Research, School of Dentistry, Prince \\ Sattam Bin Abdul-Aziz University, \\ Al-kharj, Saudi Arabia
}

Objective: The purpose of this study was to determine the effect of two extraoral computeraided design (CAD) and computer-aided manufacturing (CAM) systems, in comparison with conventional techniques, on the marginal fit of monolithic $\mathrm{CAD} / \mathrm{CAM}$ lithium disilicate ceramic crowns.

Study design: This is an in vitro interventional study.

Place and duration of study: The study was carried out at the Department of Prosthodontics, School of Dentistry, Prince Sattam Bin Abdul-Aziz University, Saudi Arabia, from December 2015 to April 2016.

Methodology: A marginal gap of 60 lithium disilicate crowns was evaluated by scanning electron microscopy. In total, 20 pressable lithium disilicate (IPS e.max Press [Ivoclar Vivadent]) ceramic crowns were fabricated using the conventional lost-wax technique as a control group. The experimental all-ceramic crowns were produced based on a scan stone model and milled using two extraoral CAD/CAM systems: the Cerec group was fabricated using the Cerec CAD/ CAM system, and the Trios group was fabricated using Trios CAD and milled using Wieland Zenotec CAM. One-way analysis of variance (ANOVA) and the Scheffe post hoc test were used for statistical comparison of the groups $(\alpha=0.05)$.

Results: The mean ( \pm standard deviation) of the marginal gap of each group was as follows: the Control group was $91.15( \pm 15.35) \mu \mathrm{m}$, the Cerec group was $111.07( \pm 6.33) \mu \mathrm{m}$, and the Trios group was $60.17( \pm 11.09) \mu \mathrm{m}$. One-way ANOVA and the Scheffe post hoc test showed a statistically significant difference in the marginal gap between all groups.

Conclusion: It can be concluded from the current study that all-ceramic crowns, fabricated using the CAD/CAM system, show a marginal accuracy that is acceptable in clinical environments. The Trios CAD group displayed the smallest marginal gap.

Keywords: conventional impression, optical impression, extraoral scanner, all-ceramic crowns

\section{Introduction}

Computer-aided design (CAD) and computer-aided manufacturing (CAM) techniques have been introduced into dentistry to simplify and improve the quality of final restorations. ${ }^{1,2}$ The inefficient use of production time and lack of technical skills are the main drawbacks of the conventional production technique. ${ }^{1}$ Various production pathways are employed to minimize inaccuracies in the final product, although the conventional lostwax method has generally been considered the gold standard of crown fabrication. ${ }^{3,4}$ The shrinkage and expansion of the material used in traditional techniques determine the marginal accuracy of the final crown. Marginal fit is a key factor in assuring the longevity of full-veneer restorations $;{ }^{5}$ a poor fit leads to cement dissolution and
Department of Prosthodontics, School of Dentistry, Prince Sattam Bin Abdul-Aziz University, PO Box I53, Al-kharj II942, Saudi Arabia

Tel +966540633399

Fax +966 I| 588620 I

Email implantologist@yahoo.com 
micro-leakage, which in turn results in recurrent caries and periodontal disease. ${ }^{6}$ A marginal discrepancy of up to 120 $\mu \mathrm{m}$ is considered a clinically acceptable threshold. ${ }^{7,8}$

The marginal opening is the most important factor in enhancing the reliability of the newly developed CAD/CAM systems. Sulaiman et $\mathrm{al}^{9}$ compared the marginal fit of three different production techniques (Procera, IPS Empress, and In-Ceram). The results showed that the mean marginal gap of the Procera group was $82.88 \mu \mathrm{m}$; for the IPS Empress group, it was $62.77 \mu \mathrm{m}$; and for the In-Ceram group, it was $160.66 \mu \mathrm{m}$. The Procera and IPS Empress crowns displayed the smallest marginal gap within the clinically acceptable range. In another study, the marginal accuracy of the conventional lost-wax technique (heat-pressed IPS Empress) and the CAD/CAM approach (Cerec 3D) was compared..$^{10}$ The mean $( \pm$ standard deviation $[\mathrm{SD}])$ marginal gaps were $56( \pm 31) \mu \mathrm{m}$ for the former and $70( \pm 32) \mu \mathrm{m}$ for the latter; there was no significant difference between the groups. In a similar study, Lee et $\mathrm{al}^{11}$ compared the marginal fit of all-ceramic crowns fabricated using two CAD/CAM systems (single-layer system Cerec 3D and double-layer system Procera). The results showed a clinically acceptable marginal fit with both the systems. Meanwhile, Baig et $\mathrm{al}^{12}$ studied the influence of two different CAD systems on the marginal fit of full-veneer all-ceramic restorations. The mean marginal gaps were $66.4 \mu \mathrm{m}$ for the Cercon system, $36.6 \mu \mathrm{m}$ for IPS Empress II, and $37.1 \mu \mathrm{m}$ for the full-veneer metal control group. The Cercon CAD system showed a statistically significant, larger marginal gap than that produced by the latter two groups. In another study, Yeo et $\mathrm{al}^{13}$ studied the marginal discrepancies of all-ceramic crowns fabricated with the Celay In-Ceram, Conventional In-Ceram, and IPS Empress II layering techniques, in comparison with a metal ceramic crown as a control group. The marginal discrepancies were $112 \mu \mathrm{m}$ for the conventional InCeram group, $83 \mu \mathrm{m}$ for the Celay In-Ceram group, $46 \mu \mathrm{m}$ for the IPS Empress II group, and $87 \mu \mathrm{m}$ for the Control group. The results highlighted a significant difference in marginal accuracy between the experimental groups.

The marginal accuracy of all-ceramic crowns is mainly affected by the various CAD/CAM production systems. ${ }^{2,14-17}$ Continuous developments and renovations of such systems have entailed extensive studies to determine the accuracy of the final milled restorations. The purpose of this study was to compare the marginal accuracy of two CAD/CAM production systems with the conventional lost-wax technique. The null hypothesis shows that the Cerec Omnicam and Trios all-ceramic crowns, that are produced digitally, have a higher marginal gap compared with those fabricated using conventional techniques.

\section{Methodology}

The sample-size calculation was based on the mean and SD, according to a similar study by Brawek et al. ${ }^{2}$ The sample of 20 specimens for each group achieved a $93 \%$ power to detect differences among the mean values, with a $0.05(\alpha)$ significance level (effect size of 0.79). Standard molar preparation with $1.5 \mathrm{~mm}$ uniform axial and occlusal reduction and $1 \mathrm{~mm}$ circular shoulder with rounded inner edges on the typodont was made using a Ney surveyor (type 990 Bestell-Nr 625 0200; Dentsply International Inc., York, PA, USA), to obtain an accurate total occlusal convergence. A chromium-cobalt ( $\mathrm{CrCo})$ master model was made from the duplicate dentoform-prepared tooth and fixed on the typodont (Figure 1). A double layer of the baseplate wax spacer (Shur Wax, Modern Materials, Heraeus Kulzer, LLC, Paterson, IN, USA) was used to fabricate 20 custom trays made of light-cured acrylic resin (SternTek, Sterngold Restorative Systems, Attlebono, MA, USA). Thereafter, 20 conventional impressions were made using light-body polyvinyl siloxane (PVS) around the prepared tooth, and heavy-body PVS impression material (Imprint II Garant, 3M ESPE, St. Paul, MN, USA) was used on the custom tray. The final impression was poured using type IV dental stone (ResinRock, Whip Mix Corporation, Louisville, KY, USA) to fabricate the working cast. A removable die was fabricated using the Pindexing system (Pindex; Coltene/Whaledent, Mahwah, NJ, USA). The experimental all-ceramic crowns (IPS e-max CAD) were fabricated from the scan stone model and milled using two extraoral CAD/ CAM systems: the Cerec group was fabricated by scanning the stone model and milled by using the Cerec Omnicam (Sirona, Bensheim, Germany) CAD/CAM system (Figure 2), while the Trios group was produced by scanning the stone model using Trios CAD (3shape, Copenhagen, Denmark) and milled using

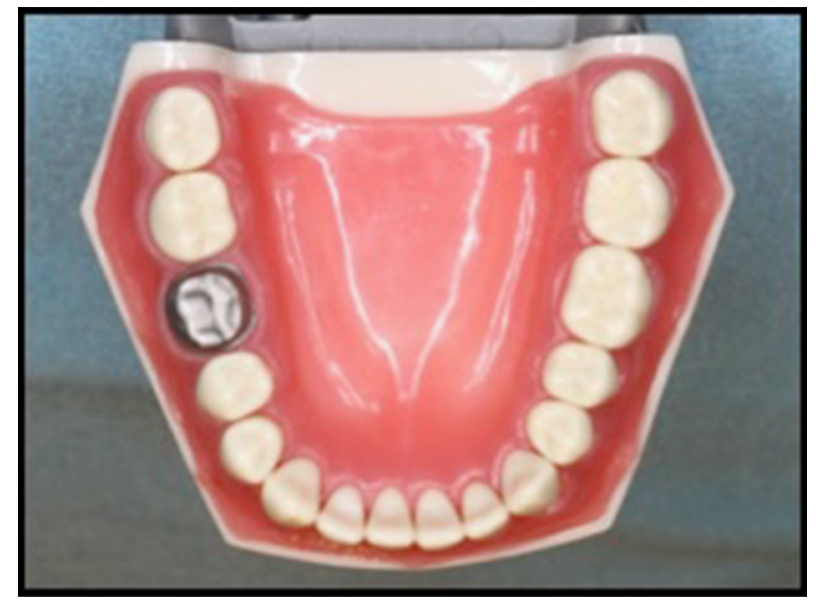

Figure I Master model fabrication with chromium-cobalt $(\mathrm{CrCo})$ master die. 




Figure 2 Cerec group cast scanning and crown designing.

Wieland CAM (Zenotec, Ivoclar Vivadent; Figure 3). The final restoration in all test groups was constructed using IPS e-max CAD (IPS e-max, Ivoclar, Amherst, NY, USA) lithium disilicate blocks in shade Vita A2. For the Control group, after complete scanning, the dyes were trimmed and prepared for the conventional full-contour wax-up. The putty index made before tooth preparation was used as a guide to standardize the latter process. The lost-wax technique was used to fabricate pressed lithium disilicate all-ceramic crowns (IPS e-max) in shade Vita A2.

None of the crowns were cemented on the master cast. ${ }^{12,16}$ A special loading device was fabricated to apply an occlusal load of $3 \mathrm{lbs}$ during the measurement. ${ }^{12}$ Four points (mid-buccal, mid-lingual, mid-mesial, and mid-distal) of the measurements were located on the master model to standardize them. The vertical distance between the finish line and the most apical part of the crown represented the marginal gap. ${ }^{18}$ The margins in each point were measured using a computer digital image analysis system, with the scanning electron microscope (JSM - 6360LV SEM, JEOL, USA) at a magnification of $50 \times$. The microscope was attached in order to charge the coupled device camera, which captured images of the margins for display on a computer monitor using image capturing and processing software. Three measurements were taken for each point, and the average was recorded.
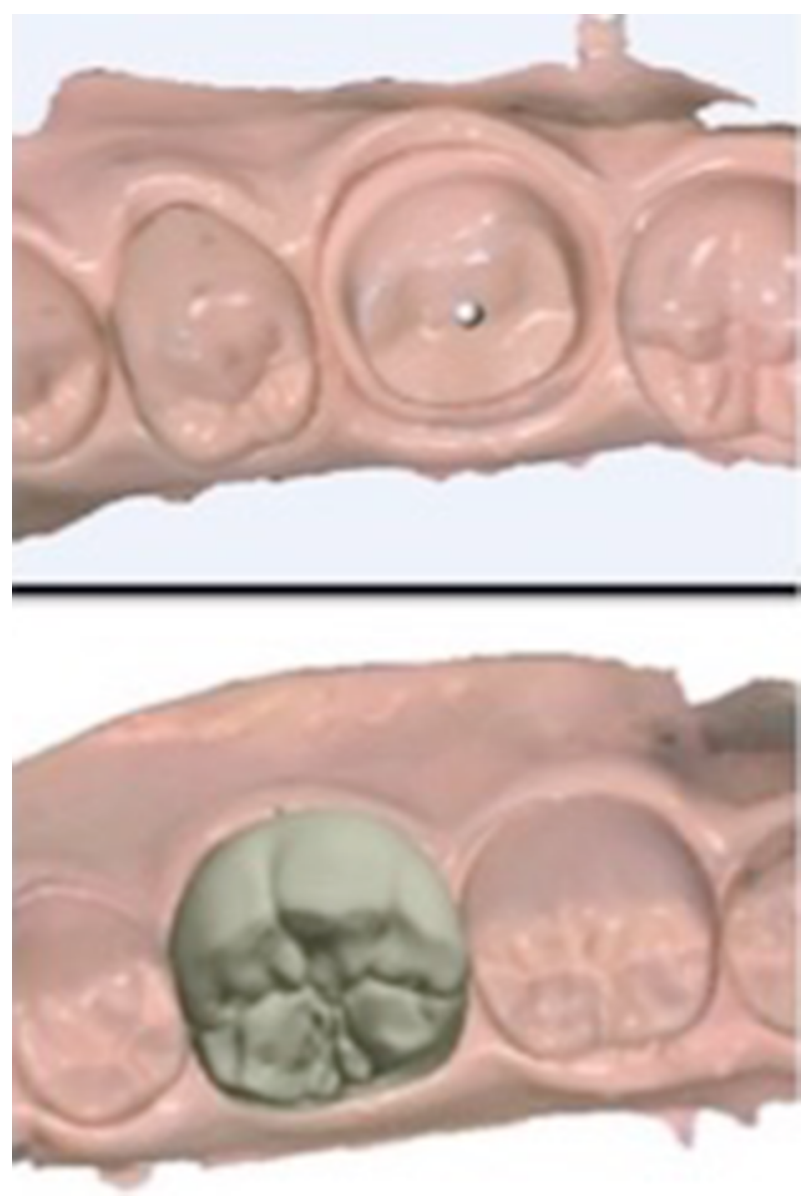

Figure 3 Trios group cast scanning and crown designing.

This study did not involve human or animal participants. For this type of study, formal consent is not required.

\section{Results}

The marginal gap for each individual specimen was measured three times at four sites, and the average was reported for each group in micrometers $(\mu \mathrm{m})$. However, the readings of the marginal gap for all crowns were recorded. The mean marginal gap for the Cerec group was higher than those for the Control and Trios groups (Table 1). The Cerec group also showed both the lowest $(39.10 \mu \mathrm{m})$ and highest $(125.20 \mu \mathrm{m})$ marginal gaps. The mean $( \pm \mathrm{SD})$ of the marginal gap of each group was as follows: for the Control group, it was 91.15

Table I Marginal gap of the crown groups by impression technique in micrometers $(\mu \mathrm{m})$

\begin{tabular}{llll}
\hline Group & Mean & Standard deviation & $\mathbf{N}$ \\
\hline Control & 91.1500 & \pm 15.35066 & 20 \\
Cerec & 111.0650 & \pm 6.32791 & 20 \\
Trios & 60.1650 & \pm 11.09425 & 20 \\
Total & & & 60 \\
\hline
\end{tabular}




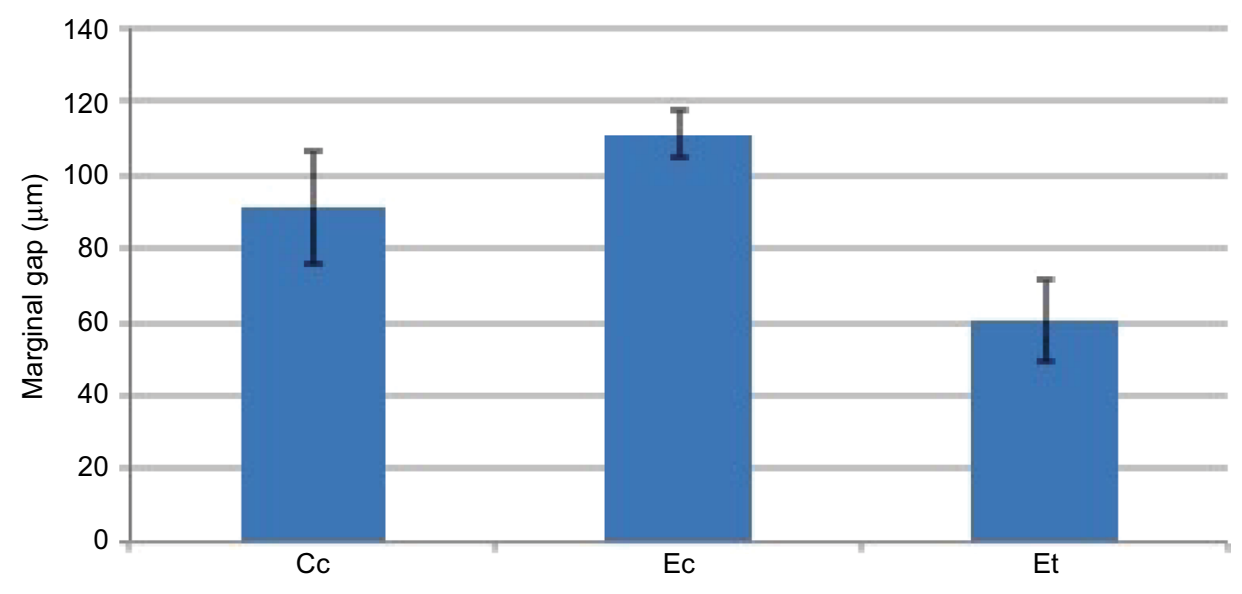

Figure 4 Mean and standard deviation of the marginal gap $(\mu \mathrm{m})$ for each group. Abbreviations: Cc, Control group; Ec, Cerec group; Et, Trios group.

$( \pm 15.35) \mu \mathrm{m}$; for the Cerec group, it was $111.07( \pm 6.33) \mu \mathrm{m}$; and for the Trios group, it was $60.17( \pm 11.09) \mu \mathrm{m}$ (Figure 4). The Shapiro-Wilk test was deployed to check for normal distribution. Next, one-way analysis of variance (ANOVA) was used to reveal statistically significant differences between the groups $(p \leq 0.05)$. These data were further analyzed using Scheffe multiple comparison post hoc tests, in order to assess individual intra-group differences $(p \leq 0.05)$.

One-way ANOVA revealed statistically significant differences in the marginal gaps between all groups $(p<0.05)$. The Scheffe post hoc test, yielding greater details, shows similar variations between the Control, Cerec $(p<0.05)$, and Trios groups $(p<0.05)$, as well as between the Cerec and Trios groups $(p<0.05)$.

\section{Discussion}

The main purposes of this study were to evaluate (in vitro) the marginal fit of all-ceramic crowns fabricated using two extraoral CAD/CAM systems (Cerec and Trios) and to compare them with those of pressed all-ceramic crowns produced by the conventional lost-wax technique. The null hypothesis was rejected based on the statistically significant difference in the marginal-gap values of conventional and $\mathrm{CAD} / \mathrm{CAM}$ fabricated crowns. The results prove that the fabrication technique has a notable effect on the marginal accuracy of the product. Trios CAD with Wieland CAM produced the smallest mean $( \pm \mathrm{SD})$ of the marginal gap at $60.17( \pm 11.09)$ $\mu \mathrm{m}$, followed by the conventional technique at $91.15( \pm 15.35)$ $\mu \mathrm{m}$, whereas the highest marginal gap was $111.07( \pm 6.33) \mu \mathrm{m}$, obtained in the Cerec group. In the same group, the lowest marginal accuracy was obtained, compared to the result from the Trios group, which may have been due to the effect of the digital scanning accuracy or that of the CAM milling systems.
The CAD, which was the technology device used to capture the data in each system, varied between them. In the Cerec system, it was designed with a triangulation-of-light concept, in which three linear lights, focused at an intersection, were used to create a point in three-dimensional space, whereas in the Trios system it worked with the principles of ultrafast optical sectioning and confocal microscopy. ${ }^{19}$ In addition, the CAM milling machines used to mill the stereolithography (STL) file in both groups differed in their number of axes, spindle movements, size and shape of the milling burs, and internal accuracy of the system. Cerec is a closed system, which cannot accept external STL files for milling; meanwhile, the generated Cerec STL file could not be read by any CAM milling systems other than Cerec milling machines, which is why two of the latter (Cerec and Wieland Dental) were used. All fabrication techniques, whether conventional or CAD/CAM, produced a clinically acceptable full-veneer crown with a marginal gap of less than $120 \mu \mathrm{m} .{ }^{8}$

The results of this study are in agreement with those of

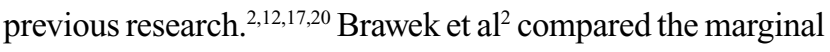
fit of two extraoral CAD/CAM systems, Lava and Cerec AC/ Inlab, with the conventional technique to find that all digitally fabricated crowns were within the clinically acceptable range. In another study, Syrek et $\mathrm{a}^{20}$ compared the marginal accuracy of crowns fabricated with Lava chairside oral scanner and the lost-wax technique. Their results showed that optical scanning and milling produced a significantly smaller marginal gap than that produced using the traditional technique. In a similar study, researchers compared crowns fabricated using the Lava COS, Cerec, and iTero scanning systems $;{ }^{17}$ the marginal accuracy of all three was similar, compared with the time-honored technique. The results found in the present study, which contrast with previously published articles, may 
be attributed to the different parameters and materials used. For example, Baig et $\mathrm{al}^{12}$ compared the marginal accuracy among full-metal crowns, IPS Empress II ceramic crowns, and the Cercon system. The results showed a significant difference in accuracy between the groups, with the Cercon system displaying the largest marginal gap.

The present study was conducted in a laboratory environment under ideal conditions, to eliminate the influence of clinical errors, such as varying parameters of tooth preparation, including bleeding, saliva, limited access, finish lines, and their effects on the conventional or optical impressions techniques. Tooth preparation was performed using the Ney surveyor to optimize the total occlusal convergence. The master model was made using CrCo material with four index points to standardize the location of the marginal-gap measurements. Custom trays were fabricated with a minimum impression space to minimize the material distortion. All of the optical and conventional impressions were carried out by one prosthodontist. The final contours of all crowns were standardized with a putty index for the conventional technique and using the recommended contour from the software library for the CAD/CAM crowns. Additionally, all parameters, including the die spacer and cement thickness in both conventional and scanner (Cerec/Trios) designs, were standardized. An uncemented crown with a $3 \mathrm{lbs}$ load was used to eliminate the effect of the luting agents on the final marginal accuracy. ${ }^{12,16} \mathrm{~A}$ limitation of this study was the use of different milling machines for each test group, which was necessary as Cerec is considered a closed system that does not accept other STL files. Therefore, the Cerec crowns were milled using the same Cerec milling machine, while the Trios crowns were milled using the Wieland Zenotec machine, which may have been a factor in the accuracy of the final restorations. Within the conditions of this study, the digital extraoral CAD/CAM systems can be considered an alternative to the conventional method.

\section{Conclusion}

Within the limitations of this in vitro experiment, the following conclusions were made:

1. All-ceramic crowns fabricated using an extraoral CAD/ CAM system showed an acceptable clinical marginal accuracy.

2. Trios CAD with Wieland Zenotec CAM showed the smallest marginal gap, compared with the conventional heat-press and Cerec CAD/CAM techniques.

It also complies with ethical standards.

\section{Disclosure}

The author does not have any financial interest in the companies whose materials are included in this article and reports no conflicts of interest in this work.

\section{References}

1. Beuer F, Schweiger J, Edelhoff D. Digital dentistry: an overview of recent developments for CAD/CAM generated restorations. Br Dent J. 2008;204(9):505-511.

2. Brawek PK, Wolfart S, Endres L, Kirsten A, Reich S. The clinical accuracy of single crowns exclusively fabricated by digital workflow - the comparison of two systems. Clin Oral Investig. 2013;17(9):2119-2125.

3. Eames WB, O'Neal SJ, Monteiro J, Miller C, Roan JD Jr, Cohen KS Techniques to improve the seating of castings. JAm Dent Assoc. 1978; 96(3):432-437.

4. Hollenback GM. A practical contribution to the standardization of casting techniques. J Am Dent Assoc. 1928;15(10):1917-1928.

5. White SN, Ingles S, Kipnis V. Influence of marginal opening on microleakage of cemented artificial crowns. J Prosthet Dent. 1994;71(3): 257-264.

6. Bindl A, Mörmann WH. Marginal and internal fit of all-ceramic CAD/CAM crown-copings on chamfer preparations. J Oral Rehabil. 2005;32(6):441-447.

7. Suárez MJ, González de Villaumbrosia P, Pradíes G, Lozano JF. Comparison of the marginal fit of Procera AllCeram crowns with two finish lines. Int J Prosthodont. 2003;16(3):229-232.

8. McLean JW, von Fraunhofer JA. The estimation of cement film thickness by an in vivo technique. Br Dent J. 1971;131(3):107-111.

9. Sulaiman F, Chai J, Jameson LM, Wozniak WT. A comparison of the marginal fit of In-Ceram, IPS Empress, and Procera crowns. Int $J$ Prosthodont. 1997;10(5):478-484.

10. Reich S, Gozdowski S, Trentzsch L, Frankenberger R, Lohbauer U. Marginal fit of heat-pressed vs. CAD/CAM processed all-ceramic onlays using a milling unit prototype. Oper Dent. 2008;33(6):644-650.

11. Lee KB, Park CW, Kim KH, Kwon TY. Marginal and internal fit of all-ceramic crowns fabricated with two different CAD/CAM systems. Dent Mater J. 2008;27(3):422-426.

12. Baig MR, Tan KB, Nicholls JI. Evaluation of the marginal fit of a zirconia ceramic computer-aided machined (CAM) crown system. J Prosthet Dent. 2010;104(4):216-227.

13. Yeo IS, Yang JH, Lee JB. In vitro marginal fit of three all-ceramic crown systems. J Prosthet Dent. 2003;90(5):459-464.

14. Schaefer O, Watts DC, Sigusch BW, Kuepper H, Guentsch A. Marginal and internal fit of pressed lithium disilicate partial crowns in vitro: a three-dimensional analysis of accuracy and reproducibility. Dent Mater. 2012;28(3):320-326.

15. Yuzbasioglu E, Kurt H, Turunc R, Bilir H. Comparison of digital and conventional impression techniques: evaluation of patients' perception, treatment comfort, effectiveness and clinical outcomes. BMC Oral Health. 2014;14:10.

16. Tidehag P, Ottosson K, Sjögren G. Accuracy of ceramic restorations made using an in-office optical scanning technique: an in vitro study. Oper Dent. 2014;39(3):308-316.

17. Seelbach P, Brueckel C, Wöstmann B. Accuracy of digital and conventional impression techniques and workflow. Clin Oral Investig. 2013;17(7):1759-1764.

18. Holmes JR, Bayne SC, Holland GA, Sulik WD. Considerations in measurement of marginal fit. J Prosthet Dent. 1989;62(4):405-408

19. Ting-Shu S, Jian S. Intraoral digital impression technique: a review. J Prosthodont. 2015;24(4):313-321.

20. SyrekA, Reich G, Ranftl D, Klein C, Cerny B, Brodesser J. Clinical evaluation of all-ceramic crowns fabricated from intraoral digital impressions based on the principle of active wavefront sampling. J Dent. 2010;38(7): $553-559$. 


\section{Publish your work in this journal}

Clinical, Cosmetic and Investigational Dentistry is an international, peer-reviewed, open access, online journal focusing on the latest clinical and experimental research in dentistry with specific emphasis on cosmetic interventions. Innovative developments in dental materials, techniques and devices that improve outcomes and patient satisfac- tion and preference will be highlighted. The manuscript management system is completely online and includes a very quick and fair peerreview system, which is all easy to use. Visit http://www.dovepress. com/testimonials.php to read real quotes from published authors.

Submit your manuscript here: https://www.dovepress.com/clinical-cosmetic-and-investigational-dentistry-journal 